\title{
Portable Micro Hydro Electrical Generator
}

\author{
Md. Mizanur Rahman ${ }^{1}$, Piyas Chowdhury ${ }^{2}$, Md. Nafees Rahman ${ }^{3}$, \\ Sadia Tasnim Mowri ${ }^{4}$, Mohammad Al Mamun ${ }^{5}$ \\ Chittagong University of Engineering and Technology (CUET), Chittagong-4349, Bangladesh \\ University of Information Technology \& Sciences (UITS), Bangladesh
}

\begin{abstract}
Micro Hydro Power Plants have many advantages over large scale hydropower generation. This has been identified as a good alternative to conventional electricity generation for many developing countries around the world. This paper presents a new concept of a Portable Micro Hydro Electrical Generator with a Permanent Magnet Synchronous Generator (PMSG).

Keywords: Hydro power, Micro-hydro power, Permanent magnet.
\end{abstract}

\section{INTRODUCTION}

World is entering in a new chapter in energy generation. Reducing $\mathrm{CO}_{2}$ emissions, increasing energy security and enhancing sustainability is the prime focus. Therefore the energy generation has to be economically sound. Demand for oil and gas resources is increasing and there is an uncertainty over the long term supply of oil and gas due to political conflicts. In addition to this, there is increased resistance for nuclear after the recent events in Fukushima. Moreover, problems with waste management and decommissioning are still present and costs keep escalating. Although coal is a cheaper alternative, emissions of greenhouse gases are significantly high and it is not a sustainable solution for long term energy generation. Therefore global energy generation must make much greater use of new renewable energy sources and will focus more upon energy efficiency. However, at present most renewable sources are not economically viable making them very unattractive for developing countries.

Nowadays, the utilization of renewable energy sources (RES) to match the increasing electric energy demand is determined by environmental concerns, fossil fuels depletion and also by economical and social aspects. Hydro power is an economically viable source of renewable energy. Also the hydro technologies are maturing for long term energy generation. Large-scale hydro power generation is affected by lack of potential sites, capital costs, long development times etc. However, these problems are curbed by Small Hydro Power (SHP) developments [1-4]. In Romania, energy production from renewable sources is based mainly on hydro power plants, as the hydro graphic network offers a large unexploited potential for micro and small plants [5]. According to the national hydroelectric company, the micro hydro power plants (MHPP) can provide powers up to $1 \mathrm{MW}$.

They can be operated in both grid-connected or in islanded mode.

\section{WHY MICRO-HYDROPOWER}

Depending on individual circumstances, many people find that they need to develop their own source of electrical power. Canada has thousands of rivers, streams and springs that could be used to generate electricity to meet the energy requirements for off-grid rural residents, cottage owners, and small communities, camp sites, parks and remote lodges.

Other renewable energy sources, such as solar and wind, can be used to produce electrical power. The choice of energy source depends on several factors, including availability, economics and energy and power requirements. Micro-hydropower systems offer a stable, inflation-proof, economical and renewable source of electricity that uses proven and available technologies. These technologies can produce as little as $100 \mathrm{~W}$ of electricity at low cost and at very competitive rates, and appropriately designed and implemented systems can provide inexpensive energy for many years.

Micro hydropower generation is the small-scale renewable energy technology and highly cost effective for sites with access to a suitable flow.

\section{Permanent Magnet}

A magnet is a material or object that produces a magnetic field. This magnetic field is invisible but is responsible for the most notable property of a magnet: a force that pulls on other ferromagnetic materials, such as iron, and attracts or repels other magnets. A permanent magnet is an object made from a material that is magnetized and creates its own persistent magnetic field. 


\section{PROPOSED DESIGN}

Hydropower Plant captures energy from water and then converts that energy into electricity. In hydroelectric plants, water flowing through a constructed dam or sometimes just through a waterwheel turns a turbine, which in-turn rotates a generator. The generator produces electricity.

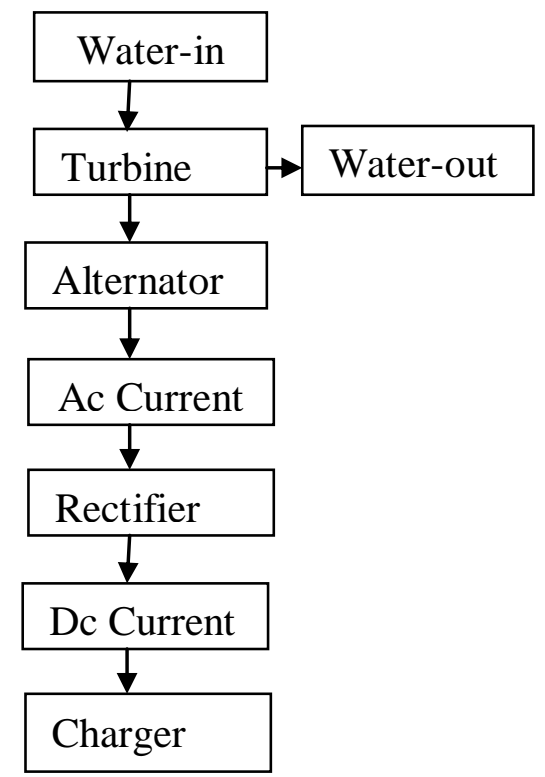

Figure.1- Block diagram of proposed micro-hydro plant

In proposed design, there is a very small scale micro-hydro electric generator for power generation. The generator has two basic parts- the stator and the rotor. The stator has the part that remains stationary and has coils of wires to collect electricity. Rotor is the part that moves. It is equipped with powerful magnets that will induce current in the coils. A water turbine that converts the energy of flowing or falling water into mechanical energy that drives a generator, which generates electrical power this, is the heart of a micro- hydropower system.

\section{A Generator}

In this design there are two parts in generator. Stator contains induction coils and rotor contains magnets. When rotor moves, conductor (coil) is fixed on the stator and the magnetic field is moved so that its flux lines are cut by the conductor and electromagnetic field are produced in it according to Faradays law of electromagnetic induction. The maximum power generation capacity of the proposed design is approximately 5 watt.

\section{B Rotor}

A rotor disc is made which is 5 inch in diameter and holes at its centre are $1 / 4$ inch in diameter. The rotor disc is movable and fixed to the shaft. It contains 4 powerful magnets and each face of the magnets determines the polarity. Magnets are arranged as such so that their polarity alternates (N-S-N-S). Then the magnets are fixed on the rotor disc using super glue. In the region surrounding magnets produce a magnetic field. From magnets magnetic flux lines radiate from North Pole to South Pole. The strength of the magnetic field in a particular region is directly related to the density of flux lines. When induction coil such as copper material is placed in the flux paths surrounding permanent magnets, there will be an almost unnoticeable change in the flux distribution.

\section{Stator}

For designing stator, firstly 4 tight coils using 800 wraps or turns are made, 8 short $(4 \mathrm{~cm})$ strips of electrical tape are cut and after then these are set aside. Using a small sand paper, the enamel insulation is removed from the ends of each lead, exposing above $1 \mathrm{~cm}$ of bare wire. The coils are arranged so that their windings can alternate between clockwise and counter clockwise. A stator disc of 5 inch in diameter and holes at its center $1 / 2 \mathrm{~cm}$ in diameter are made. When coil arrangements are perfect, then the stator disc is fixed on the container. 


\section{Turbine}

A turbine is a type of engine that can extract energy from a fluid, such as water, steam, air, or combustion gases. A plastic turbine is used whose diameter is 4 inch. It is an Induction motor cooling fan. It has 12 no. of blades which is selected in this turbine for easy availability and light weight.

\section{E Shaft}

Shaft is a mechanical component for transmitting energy (torque and rotation), usually used to connect other components of a drive train that cannot be connected directly because of distance or the need to allow for relative movement between them. A mild steel rod is used as a shaft, which has a length of $37 \mathrm{~cm}$ and $1.0 \mathrm{~cm}$ diameter. A hole is made that is $1.5 \mathrm{~mm}$ across its peripheral edge at one end. The turbine is locked at this end.

\section{F Container}

The container used here is made of rejected iron sheet of $4 \mathrm{~mm}$ and $2 \mathrm{~mm}$ thick.

Length

Width

$24 \mathrm{~cm}$

Height

$22 \mathrm{~cm}$

It is welded carefully to prevent any leakage. A hole is drilled on each length plate to slide the shaft.

\section{DATA \& ANALYSIS}

Table 1 shows the generation of electrical power for different water head. From the following table it is clear that, as water head increases simultaneously generation of electrical power increases. Proposed system is designed so that, this portable micro hydro electric generator can generates maximum power of 5 Watt.

Figure 2 to 5 shows different condition on respect to water head. Figure2 shows that, whenever water head increases, voltage generation also increases which increases current. Similarly as water head increases, water flow rate increases. Final result is the electrical power generation which also increases.

\section{TABLE1: GENERATION OF EleCtricAl POWER FOR DIFFERENT WATER HEAD}

\begin{tabular}{|l|l|l|l|l|l|}
\hline $\begin{array}{c}\text { Water } \\
\text { Head } \\
\text { Meter })\end{array}$ & $\begin{array}{l}\text { Water } \\
\text { Flow } \\
\text { Rate } \\
\text { (liter/sec) }\end{array}$ & $\begin{array}{l}\text { Rotor } \\
\text { Speed } \\
(\mathrm{rpm})\end{array}$ & $\begin{array}{l}\text { Voltage } \\
(\text { Volt })\end{array}$ & $\begin{array}{l}\text { Current } \\
(\mathrm{mA})\end{array}$ & $\begin{array}{l}\text { Power } \\
\text { (Watt) }\end{array}$ \\
\hline 1.7 & 0.63 & 456 & 18 & 150 & 2.7 \\
\hline 1.8 & 0.67 & 518 & 19 & 160 & 3.04 \\
\hline 1.9 & 0.71 & 542 & 20 & 173 & 3.46 \\
\hline 2.0 & 0.75 & 550 & 22 & 192 & 4.224 \\
\hline 2.1 & 0.76 & 554 & 23 & 202 & 4.646 \\
\hline
\end{tabular}

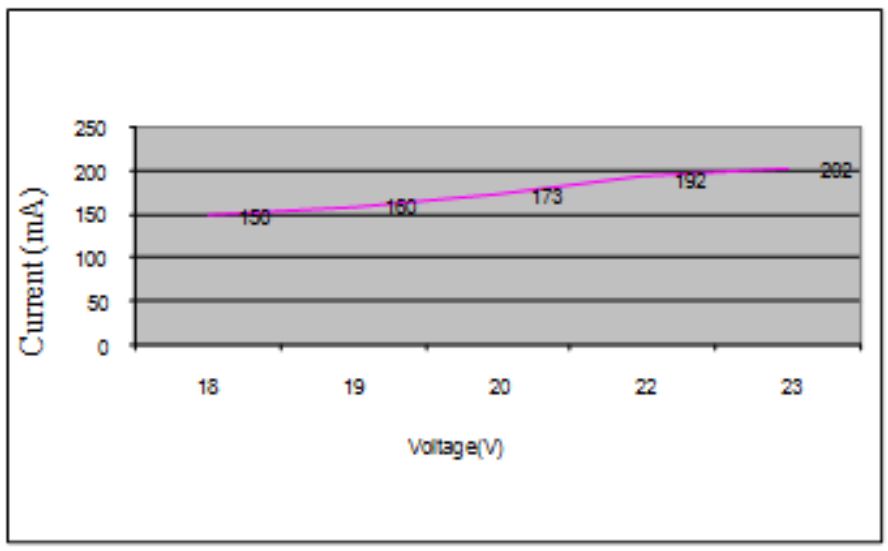

Figure.2: Current (mA) Vs Voltage (V) 


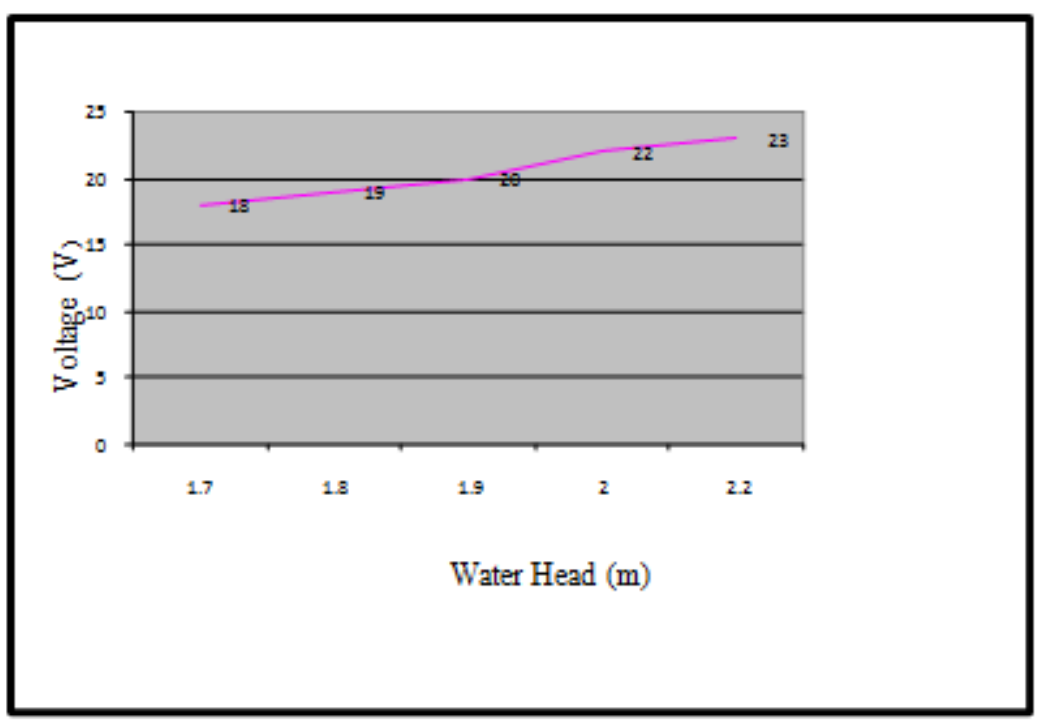

Figure.3: Voltage (V) Vs Water Head (m)

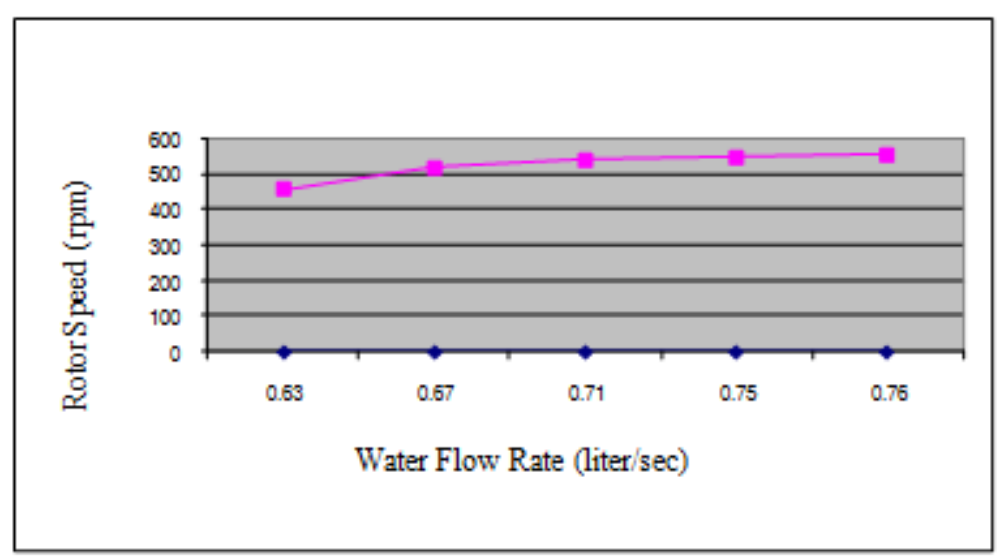

Fig.ure 4: Rotor Speed (rpm) Vs Water Flow Rate (iter/sec)

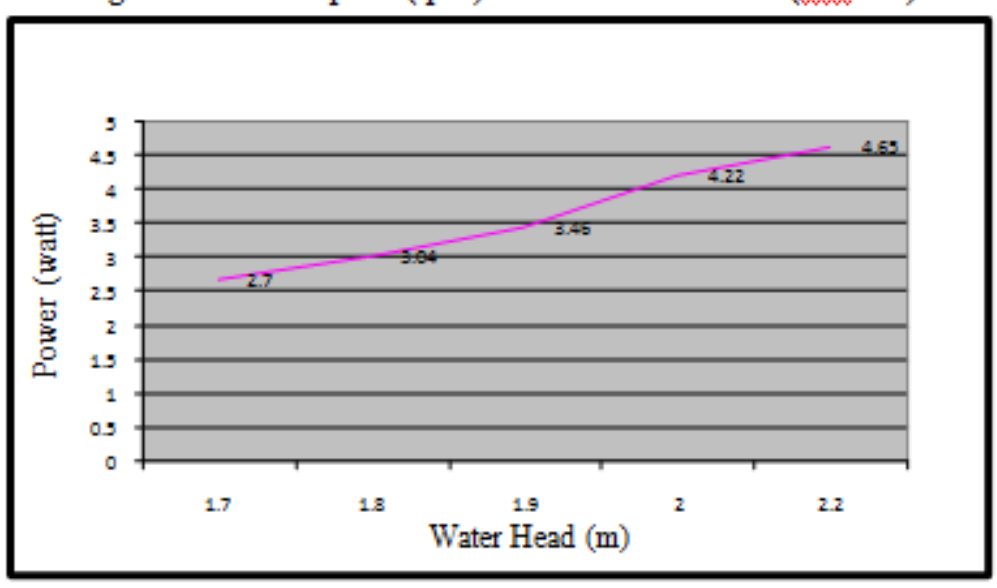

Figure.5: Power (watt) Vs Water Head (m)

\section{CONCLUSION}

Micro Hydro Power plant is an environmentally friendly, sustainable and economically viable source of energy. It is a good solution for global energy problem. This paper proposes a design of micro-hydro power plant equipped with permanent magnets. The construction of this design is so simple and its maintenance is also so easy. 


\section{REFERENCES}

[1]. Scientific and technological reference energy technology indicators, Working Document, European Small Hydropower Association, 2010.

[2]. Celso Penche, Layman's Guidebook on how to develop a small hydro site, Handbook, European Commission, 1998.

[3]. British Hydropower Association, www.british-hydro.org.

[4]. Small Hydro Power Handbook, http://www.smallhydropower.com/manual3.htm.

[5] Budisan Nicolae, Prostean Octavian, Robu Nicolae, Filip Ioan. Revival by automation of induction generator for distributed power systems in Romanian academic research. Renewable Energy 2007;32:1484-96. 